\title{
Using Movement Games in Physical Education Class to Improve Physical Fitness and Stabilize Vestibule for Children Aged 6 to 7 years
}

\author{
Chanh Thuc Dao ${ }^{1,2}$ \\ ${ }^{1}$ Department of Physical Education, An Giang University, Vietnam \\ ${ }^{2}$ Vietnam National University, Ho Chi Minh City, Vietnam
}

Received September 1, 2021; Revised October 19, 2021; Accepted November 11, 2021

\section{Cite This Paper in the following Citation Styles}

(a): [1] Chanh Thuc Dao , "Using Movement Games in Physical Education Class to Improve Physical Fitness and Stabilize Vestibule for Children Aged 6 to 7 years, "International Journal of Human Movement and Sports Sciences, Vol. 9, No. 6, pp. 1396 - 1402, 2021. DOI: 10.13189/saj.2021.090636.

(b): Chanh Thuc Dao (2021). Using Movement Games in Physical Education Class to Improve Physical Fitness and Stabilize Vestibule for Children Aged 6 to 7 years. International Journal of Human Movement and Sports Sciences, 9(6), 1396 - 1400. DOI: 10.13189/saj.2021.090636.

Copyright $\bigcirc 2021$ by authors, all rights reserved. Authors agree that this article remains permanently open access under the terms of the Creative Commons Attribution License 4.0 International License

\begin{abstract}
The purpose of this study was to determine the effectiveness of motor games to improve physical fitness and vestibular stability in primary school students aged 6-7 years. The study was carried out based on semi-boarding primary schools in Ho Chi Minh City, Vietnam. The study was carried out with 142 students in grade 1 and grade 2, who are divided into four groups (male and female experimental group; male and female control group). The indicators of fitness status and vestibular stability of 6-7-year-old students before and after using motor games during PE lessons showed superiority compared to the control group. The study showed positive effects of guiding motor games and outdoor games on fitness status and vestibular stability. The indicators of fitness and vestibular stability of students in the experimental group are higher than the control group and their reliability $(\mathrm{p}<0.05)$. Therefore, it is important to research and select the movement games suitably for the characteristics and interests of students and organize their application in practice. In reality, through the process of using conventional scientific research methods in the field of physical education, this study has selected four new movement games to help develop physical fitness and vestibular stability for primary school students aged 6-7 years old in Ho Chi Minh City and apply it in practice. The study process is carried out in two forms: Educational outdoor activities and extracurricular activities in the
\end{abstract}

Physical Education period. The initial results of the application showed that the selected motor games have developed physical strength, stabilized the vestibule for primary school students aged 6-7 in Ho Chi Minh City, and created excitement in the physical education classes for primary school students.

Keywords Movement Games, Physical Education, Vestibular Stabilization, Primary School Student, Physical Fitness

\section{Introduction}

Physical education and sports are related, especially at school age [18], [22]. Modern education increasingly emphasizes the importance of PE in schools for the health of children of all ages [1], [16]. From the first lessons in PE at school, a teacher's main goal is the holistic harmonious development of students [11]. Physical education at school is the main form of physical training and focus. Students get the necessary motor activities, games, especially at primary school age. The total development of school-age children without active physical training is impossible. Each hour of physical education should give the tasks about physical activity and 
health promotion to make students interested in physical exercises and encourage them to be active [7], [26]. To create excitement for students to learn physical education (PE), teachers need to create games to improve the physical development of children. Therefore, the movement game is a means of physical education and a conscious activity to achieve the results and the goals.

Movement games consist of two elements: Entertainment, satisfying mental needs; Physical education and upbringing contribute to moral education, will, courage, solidarity to form and develop the necessary qualities, skills, and techniques for life. Games are integrated activities, bringing comprehensive physical training, making students more agile, skillful, and stronger. While playing, the children use basic and natural motor skills such as running, jumping, throwing, climbing, crawling, turning, etc., which are used regularly, thereby stimulating physical development [25].

Unfortunately, the current physical education programs in schools do not take into account certain features such as the lack of applications of games during PE lessons and the lack of gyms or equipment in schools [19], [11]. Primary school is the most important level of education in the national education system. For primary school students, entertainment is an activity that plays an important role in mental and physical development. Children accumulate knowledge, life skills, personality formation, and entertainment through fun activities [22]. The form and method of organizing extracurricular activities in primary schools are still poor, so the results of physical education and physical training of primary school students in Ho Chi Minh City are still low.

In particular, the organization of movement games in the extracurricular program is still limited, which may be due to the lack of facilities, the lack of physical education teachers, and the students' not being able to enjoy their favorite sports. That is why we conducted this study. In addition, movement games allow you to effectively use the individual approach needed when working with children since each person is unique and has the level of development [3], [2]. Therefore, we only propose to add some movement games to the standard physical education program for 6-7-year-olds, in contrast to some studies suggesting new methods [8], [14]. Through a preliminary survey of primary schools in Ho Chi Minh City shows that Extracurricular sports activities are still underdeveloped in primary schools, forms, and methods of organizing extracurricular physical training movements. Primary schools are still poor, so the results of physical education and physical training of primary school students in general and especially those of 6-7 years old in HCMC are still low. Therefore, the problem of choosing the gymnastics suitable for the psycho-physiological characteristics of 6-7-year-old students for practical application is an important and necessary job, contributing to the development of physical strength, stabilizing the vestibule for students aged 6-7-year-old in particular, and improving the effectiveness of physical education for primary schools in Ho Chi Minh City in general.

\section{Materials and Methods}

The research process uses the following research methods: Document search analysis method. We analyzed the data with SPSS 20.0 software to make statistical results [10]. Experiment with 4 new games and physical education subjects is selected by the authors to apply to the experimental group including: "parkour games"; "Leaning and jumping parkour games"; "team play with hulo hoop"; "balance game".

Experimental subjects were divided into 2 groups:

+ Experimental group: 72 students (34 boys and 38 girls) aged 6-7 from 3 primary schools in Ho Chi Minh City. This subject practices according to the standard Physical Education program of the Ministry of Education [20] and is allowed to use the movement games that the author chooses to apply class time (specifically 2 hours/week) and extracurricular activities in Physical Education. (Specifically on Tuesday and Friday afternoons with a duration of 30 minutes/session).

+ Control group: 70 students (35 boys and 35 girls) aged 6-7 years old from 3 primary schools in HCMC. This subject participates in the main physical education course according to the regulations of the Ministry of Education and Training, Vietnam [20].

- Time of experiment: The games are experimented on by us in the extracurricular PE class, specifically in educational activities outside of class time and in extracurricular activities in Physical Education.

- Inspection and evaluation: Testing and evaluation are carried out at the time before and after the experiment.

The study uses 6 test physical fitness for students [12], [21], [22]. One test of vestibular stability "Turns on the gym bench (number of times)" [24], [15] Students tested for vestibular stability performed the exercise on a narrow surface of an exercise bench. The number of turns is calculated with an accuracy of 0.5 turns on the bench. If a student falls, they should get up and continue the exercise. Result: number of executions in 20 seconds.

- Building the experimental process: The experimental process was conducted for 9 months, specifically from September 2019 to May 2020). -Experimental location: 03 primary schools in Ho Chi Minh City; including 142 primary school students 6-7 years old. 


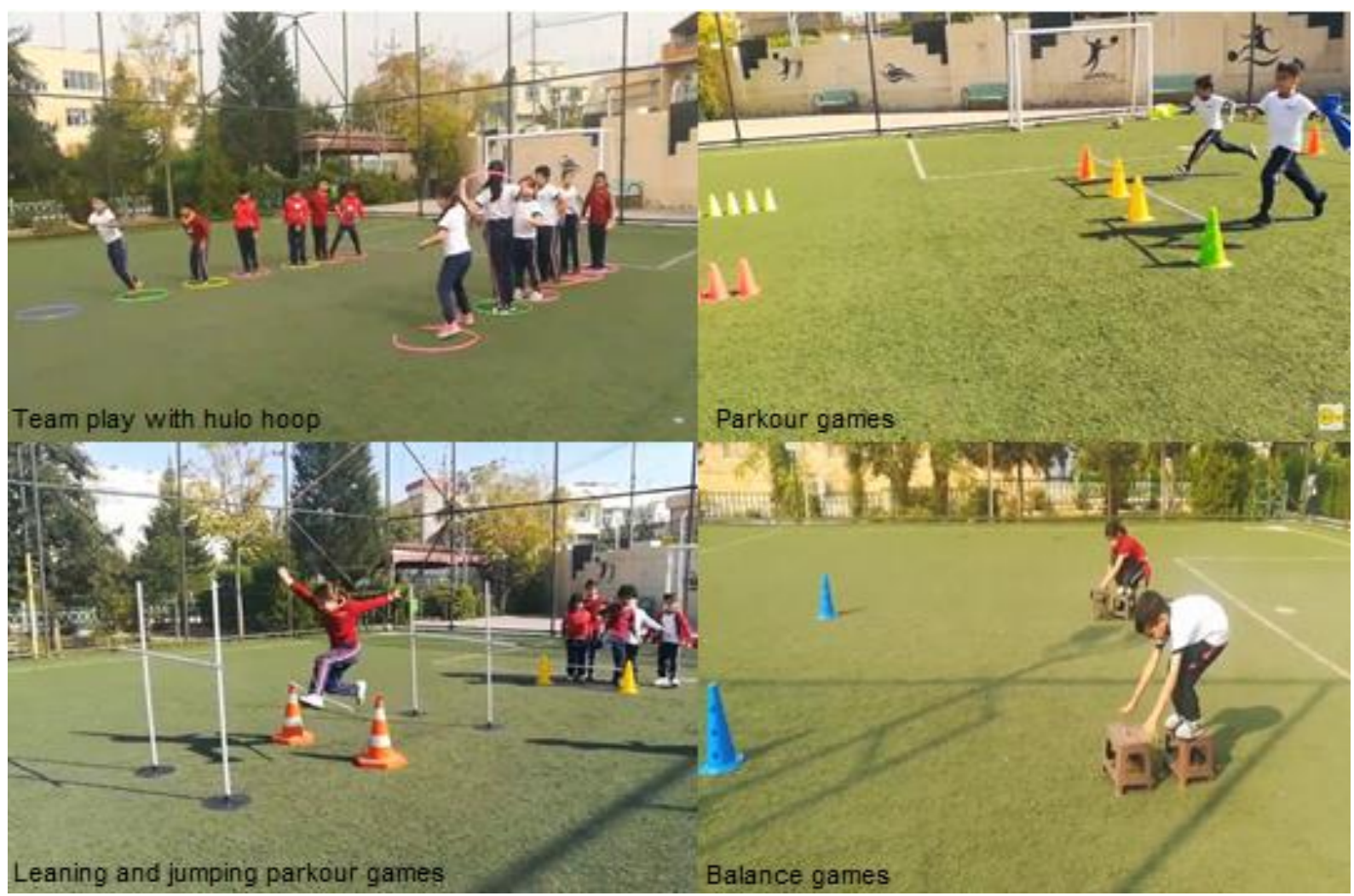

\section{Result}

The results showed that before the experiment, the fitness level and the vestibular stability index of the two groups were similar. The results of the clustering are completely objective. After the experiment, the results showed that, after one year of experimental study, the fitness level of the experimental group (EG) was higher than that of the control group (CG), which proves that the movement games that we selected and applied for primary school students aged 6-7 years old. It was highly effective in developing physical strength and stabilizing the vestibule for the experiment.

In order to see the difference more clearly in fitness indexes and vestibular stability of the experimental group and the control group, we calculated the growth rate of the physical fitness level of male and female students in the control group and the control group experiment.
The results are presented in Table 1 and Table 2.

The results of Table 1 and Table 2 show that after experimenting with 4 games, both experimental male and female groups have a higher growth in fitness level and vestibular stability than the control group.

Specifically, in the experimental group of men, the fitness test index increased from (10.55\% to $28.49 \%$ ), which outperformed the control group (3.27\% to $22.10 \%)$,

The vestibular stability index of male EG subjects increased by $41.62 \%$, surpassing that of male CG subjects by $12.43 \%$.

In the experimental female group, the index of physical fitness test increased from $9.12 \%$ to $27.64 \%$ ), which outperformed that of the control group (2.01\% to $13.31 \%)$, the index of vestibular stability in the EG female population increased by $37.91 \%$, surpassing that of the female CG superiority is $16.06 \%$. 
Table 1. Comparison of test results of fitness level and vestibular stability of 6-7-year-old male students before and after the experiment

\begin{tabular}{lcccccccc}
\hline TEST & \multicolumn{2}{c}{ CG (n=35) } & W & P & \multicolumn{2}{c}{ EG (n=34) } & W & P \\
& $\boldsymbol{M}_{\mathbf{1}}$ & $\boldsymbol{M}_{\mathbf{2}}$ & & & $\boldsymbol{M}_{\mathbf{1}}$ & $\boldsymbol{M}_{\mathbf{2}}$ & & \\
\hline Running 30 m, (s) & 6.98 & 6.63 & 5.14 & $>0.05$ & 7.04 & 6.31 & 10.94 & $<0.05$ \\
Standing long jump (cm) & 125.49 & 139.35 & 10.47 & $>0.05$ & 126.29 & 150.65 & 17.59 & $<0.05$ \\
$\begin{array}{l}\text { Lifting the torso from the prone } \\
\text { position, for 30s (times) }\end{array}$ & 11.61 & 13.55 & 15.42 & $<0.05$ & 11.71 & 14.98 & 24.50 & $<0.05$ \\
Handgrip test right, kg & 12.84 & 16.03 & 22.10 & $<0.05$ & 12.79 & 17.04 & 28.49 & $<0.05$ \\
Shuttle run 4x9 m (s) & 13.06 & 12.64 & 3.27 & $>0.05$ & 13.07 & 11.76 & 10.55 & $<0.05$ \\
5-minute run (m) & 731.35 & 758.8 & 3.68 & $>0.05$ & 722.98 & 811.96 & 11.59 & $<0.05$ \\
Turns on the gym bench (times) & 8.3 & 9.4 & 12.43 & $>0.05$ & 7.8 & 11.9 & 41.62 & $<0.05$ \\
\hline
\end{tabular}

Notes: $\mathrm{M}_{1}$, Mean value before experiment; $\mathrm{M}_{2}$, mean value after experiment

Table 2. Comparison of test results of fitness level and vestibular stability of 6-7-year-old female students before and after the experiment

\begin{tabular}{cccccccccc}
\hline TEST & \multicolumn{2}{c}{ CG (n=35) } & W & P & \multicolumn{2}{c}{ EG (n=38) } & W & P \\
& $\boldsymbol{M}_{\mathbf{1}}$ & $\boldsymbol{M}_{\mathbf{2}}$ & & & $\boldsymbol{M}_{\mathbf{1}}$ & $\boldsymbol{M}_{\mathbf{2}}$ & & & \\
\hline Running 30 m, (s) & 7.54 & 7.39 & 2.01 & $>0.05$ & 7.61 & 6.87 & 10.22 & $<0.05$ \\
Standing long jump (cm) & 121.75 & 130.19 & 6.70 & $<0.05$ & 120.82 & 140.65 & 15.17 & $<0.05$ \\
Lifting the torso from the prone & 10.37 & 11.85 & 13.32 & $<0.05$ & 10.74 & 13.84 & 25.22 & $<0.05$ \\
position, for 30s (times) & 11.95 & 13.06 & 8.88 & $>0.05$ & 11.66 & 15.4 & 27.64 & $<0.05$ \\
Handgrip test right, kg & 14.4 & 14.08 & 2.25 & $>0.05$ & 14.42 & 13.16 & 9.14 & $<0.05$ \\
Shuttle run 4x9 m (s) & 671.77 & 692.48 & 3.04 & $>0.05$ & 668.76 & 732.63 & 9.12 & $<0.05$ \\
5-minute run (m) & 6.3 & 7.4 & 16.06 & $>0.05$ & 6.2 & 9.1 & 37.91 & $<0.05$ \\
Turns on the gym bench (times) & & & & & & & & &
\end{tabular}

Notes: $\mathrm{M}_{1}$, Mean value before experiment; $\mathrm{M}_{2}$, mean value after experiment

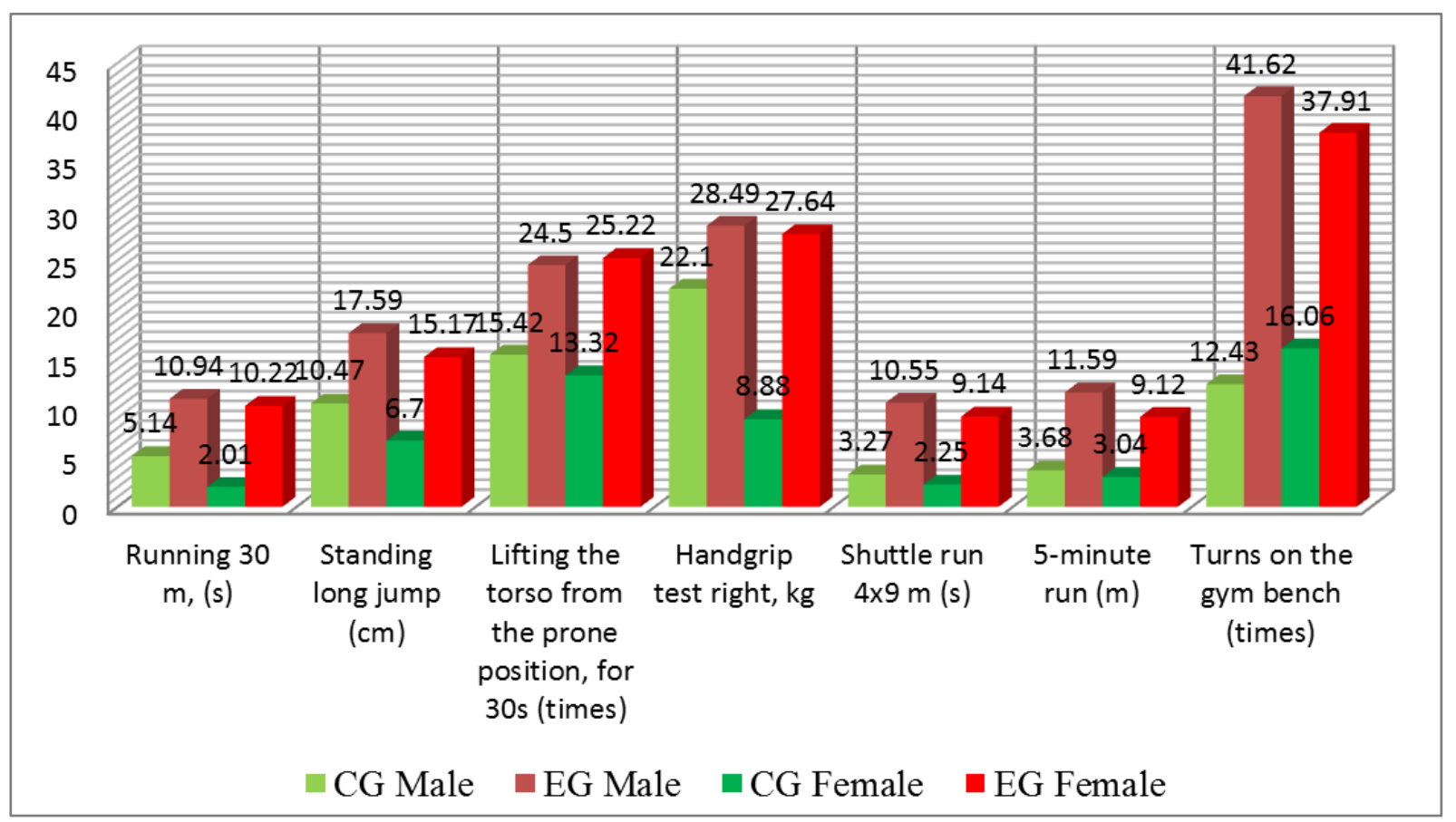

Charts 1. Levels of physical fitness index growth and vestibular stability of EG and CG

It can be seen the growth rate after the experiment, the indicators of fitness level, and vestibular stability of the two control and experimental groups of each index through charts 1. 


\section{Discussion}

The experimental research was conducted through a team of PE teachers at three primary schools and the teachers who are specifically trained in the experimental content. By the end of the training, 100 percent of the teachers have firmly grasped how to apply the movement games to the extra-curricular hour's PE that the topic has chosen.

Thus, the application of the selected geographies of the study in practice the way of experimental organization and effectiveness evaluation is conducted scientifically and rationally. These are the basic conditions to ensure the effective evaluation of the program application accurately and objectively with the highest efficiency.

Current and unfavorable environmental conditions have a big negative impact on the growth and development of the human body. A lot of research has been devoted to a healthy lifestyle, but the importance of exercise for one needs to be highlighted separately. Physical culture is a set of exercises with the aim of the holistic harmonious development of the person and their adaptability in preparation for life. The important knowledge about physical education is shown at school age. Physical education at school is a compulsory subject, so the results of student's activities in the lessons are aggregated annually [4], [7], [26].

The standard school physical education program includes a series of important movements and exercises that students learn during their time in school [19]. Some authors believe that the standard program does not need to be supplemented but completely replaced by another method or some suitable exercises [14], [8], [9].

In our opinion, this unusual measure is not entirely correct. The curriculum for elementary schools requires only minor additions. For example, the new movement games, previously studied motor play exercises are positive for children's physical development and vestibular stabilization.

The effectiveness of the movement games in the physical education curriculum for primary school-age children is proven. This game increases the movement density of physical education classes and improves the physical fitness of students [20]. This study confirms the relationship between physical ability and previously demonstrated mental and cognitive processes [5], [6], [23].

In this one study, the effect of motor games has no effect not only on the development of motor coordination processes but also on the vestibular stability of students.

Through that, we need to note the effectiveness of using a different approach in working with children. This approach is of great importance to the personal development of the student. The effectiveness of this method has been confirmed by previous studies [3], [2], [17]. The results have proved the necessity and effectiveness of the rational use of movement games in PE. The results achieved as set out goals are to contribute to the physical fitness development and stabilization of the vestibule for children 6-7 years old. Besides, it has created an exciting physical education subject for students, and at the same time increased the excitement of practicing sports for primary school students. One of the most important conditions for increasing the effectiveness of the movement games takes into account the tendencies, needs, and preferences of the students.

The pedagogical experimental results of the current study focuses on four characteristics (intellectual level, personality development characteristics, physiological development process, and language development level). Assigning moderate tasks during exercise will have a "positive" effect on the physical quality of students [11]. The body gradually completes through these pragmatic and natural exercise activities. Therefore, the physical education environment needs to create the maximum satisfaction of the needs of motor activities, an appropriate and suitable psychological state for the content of physical education in elementary schools [11].

\section{Conclusions}

The research results have proved the necessity and effectiveness of the rational use of movement games in gymnastics hours. The results achieved as set out goals are to contribute to the physical fitness development and stabilization of the vestibule for primary school students aged 6-7. Experimental research on movement games new and used in physical education classes to improve physical strength for students in primary schools in Ho Chi Minh City, Vietnam is necessary for the current school education. This process contributes to solving the problem of finding a way to organize educational activities and the problem of effectively implementing the task of physical education is through a new form of organization. The gyms that we researched and selected are highly appreciated by experts for their feasibility, practicality, ensuring development, and matching the characteristics of research subjects. It brings physical fitness development and stabilizes the vestibule for students aged 6-7 years. Through the research process, four movement games have been selected to improve physical fitness and stabilize the vestibule for primary school students aged 6-7 years old in Ho Chi Minh City. Experimental research results of movement games in practice and evaluation of effectiveness. The results showed that the movement games were highly effective in developing physical strength and stabilizing the vestibule for primary school students aged 6-7 years in Ho Chi Minh City, which is reflected in the growth rate of the indicators of physical activity of the experimental group which was higher than that of the control group. 


\section{REFERENCES}

[1] Atkinson M. "Physical cultural studies [Redux]". Sociology of Sport Journal, vol.28, no.1, p.135-144, 2011. https://doi.org/10.1123/ssj.28.1.135

[2] Barker D, Quennerstedt M, Annerstedt C. "Learning through group work in physical education: a symbolic interactionist approach." Sport, Education and Society, vol.20, no.5, p.604-623, 2015. https://doi.org/10.1080/1357 3322.2014.962493

[3] Breuer C, Hallmann K, Wicker P. Determinants of sport participation in different sports. Managing Leisure, 16(4), p.269-286, 2011. https://doi.org/10.1080/13606719.2011.61 3625

[4] Carpenter P, Morgan K. Motivational Climate, Personal Goal Perspectives, and Cognitive and Affective Responses in Physical Education Classes. European Journal of Physical Education, vol.4, no.1, p.31-44, 1999. http://dx.doi.org/10.1 080/1740898990040103

[5] Chaddock-Heyman L, Hillman CH, Cohen NJ, Kramer AF. The importance of physical activity and aerobic fitness for cognitive control and memory in children. Monographs of the Society for Research in Child Development, 79(4): 25-50, 2014. https://doi.org/10.1111/mono.12129

[6] Chang EC-H, Chu C-H, Karageorghis CI, Wang CC, Tsai JH-C, Wang Y-S, Chang Y-K. Relationship between mode of sport training and general cognitive performance. Journal of Sport and Health Science, vol.6, no.1, p.89-95, 2017. https://doi.org/10.1016/j.jshs.2015.07.007

[7] Chen S, Kim Y, Gao Z. The contributing role of physical education in youth's daily physical activity and sedentary behavior. BMC Public Health, vol.14, 2014. https://doi.org/10.1186/1471-2458-14-110

[8] Chiodera P, Volta E, Gobbi G, Milioli MA, Mirandola P, Bonetti A, Delsignore R, Bernasconi S, Anedda A, Vitale M. Specifically designed physical exercise programs improve children's motor abilities. Scandinavian Journal of Medicine and Science in Sports, vol.18, no.2, p.179-187, 2008. https://doi.org/10.1111/j.1600-0838.2007.00682.x

[9] Dallolio L, Ceciliani A, Sanna T, Garulli A. Proposal for an Enhanced Physical Education Program in the Primary School: Evaluation of Feasibility and Effectiveness in Improving Physical Skills and Fitness. Journal of physical activity \& health, vol.13, no.10, p.1024-1034, 2016. DOI:10.1123/jpah.2015-0694

[10] Dao C.T, "Measurement in sports". LAP LAMBERT Academic Publishing, ISBN 978-613-9-90198-2.2018

[11]Dao C.T, Nguyen V.T, “Students' Difficulties in the Practice of Volleyball in School Physical Education: An Analysis Based on Tactical Principles". International Journal of Human Movement and Sports Sciences, 9(1), p.41-47, 2021. DOI: 10.13189/saj.2021.090106

[12] Dao CT, "Building The Model Of Recreational Sports Club For Students Of An Giang University, Vietnam", Innovative Journal of Medical and Health Science, vol. 9, no. 4, p.384-394, 2019.

[13] Dao CT., Huynh TK, “The Influence of Recreational Sports Clubs on the Physical Health and Confidence- Social Health Development of Participants: A Study of Recreational Sport Clubs a University", Innovative Journal of Medical and Health Science, vol.9, no.6, p.468-74, 2019. https://doi.org/10.15520/ijmhs.v9i6.2606.

[14] Dobbins M, Husson H, DeCorby K, LaRocca RL. School-based physical activity programs for promoting physical activity \& fitness in children and adolescents aged 6 to 18. Cochrane Database of Systematic Reviews, vol. 2, 2013. https://doi.org/10.1002/14651858.CD007651.pub2

[15] Georgy G P. The Development of the Vestibular Stability in Children Who are Engaged in Football Taking into Account their Nervous System. Indian Journal of Public Health Research \& Development, vol.10, no.2, p.317-322, 2019.

[16] Gregor S, Janko S. "Influence of the quality implementation of a physical education curriculum on the physical development and physical fitness of children". BMC public health, vol.12, 2012. https://doi.org/10.1186/1471-2458-1261

[17] Kühnhausen J, Dirk J, Schmiedek F. Individual classification of elementary school children's physical activity: A time-efficient, group-based approach to reference measurements. Behaviour Research Methods, vol.49, no.2, p.685-697, 2016. DOI: 10.3758/s13428-016-0724-2

[18] Lelonek M, Przychodni A. Level of physical activity during school recess within aspect of available dedicated playing space. Phys Activ Rev, vol. 8, no.2, p.30-37, 2020. doi: 10.16926/par.2020.08.19

[19] Lyakh VI. Physical culture. Grades 1-4: Textbook for general education institutions. - Moscow: Education 2013;190 p.

[20] Ministry of Education and Training, "Promulgating Regulations on organization of extracurricular sports activities for pupils and students", Hanoi, Vietnam, 2008. (In Vietnamese)

[21] Natal'ya M, Mikhail K, Elena R, Evgenii T, Sergey U, Evgeny T, Andrey G, Elena K, Anton V, Dulamjav P ., "Pilates program use for high school girls' additional physical education". Journal of Physical Education and Sport, Vol.20, no.6, p.3485 - 3490, 2020.

[22] Nemček D, Pačesova P, Smela P, Ladecka L, Harcarikova T. Health status differences in subjective well-being of male and female high school students preferring sedentary leisure activities. Phys Activ Rev, vol. 8, no.2, p.1-8, 2020. doi: 10.16926/par.2020.08.15

[23] Pietsch S, Böttcher C, Jansen P., Cognitive Motor Coordination Training Improves Mental Rotation Performance in Primary School-Aged Children. Mind, Brain, and Education, 11(4), p.176-180, 2017. https://doi.org/10.1111/mbe.12154

[24] Polevoy G. G., "Use of Exercise Classics in Physical Education Classes for the Development of Vestibular Stability of Schoolchildren", International Journal of Human Movement and Sports Sciences, vol.9, no.2, p.180-184, 2021. DOI: 10.13189/saj.2021.090203

[25] Tran D L., "100 Movement games for primary school students," Pedagogical University Publishing House, Hanoi, 1997. (In Vietnamese) 
[26] Wallhead T, Garn A, Vidoni C. Sport Education and social goals in physical education: relationships with enjoyment, relatedness, and leisure-time physical activity. Physical
Education and Sport Pedagogy, 18(4): 427-441, 2012. https://doi.org/10.1080/17408989.2012.690377. 